\title{
Behavioral Tests on Murine Models with Gelsemium sempervirens
}

\section{Salvatore Chirumbolo*}

Department of Medicine-Section D, Ospedale Civile Maggiore-Lato Mameli-Ospedale Geriatrico, Italy

\section{Dear Sirs,}

Recently reported commentaries [1,2] have raised the question how much experimental settings employed in complementary and alternative medicine fit to the accepted rules of reliability and best performance that are required for a good scientific research; in this context, I firmly believe that biases are thoroughly to be faced during any investigation. Alcohol used in experiments reported in $[3,4]$ is an example. According to the Authors [2-4] diluted doses of Gelsemium sempervirens did not provoke any sedation side-effect [2]. However, as each dose used in experimental settings, contained $0.3 \%$ ethanol and as each mouse underwent i.p. injections for 9 days [3] or 7-8 days [4], a simple calculation allows to estimate that each subject received throughout the indicated period a total amount of $6.00-7.00 \mathrm{mg}$ ethanol, considering an administration of $1.0 \mu \mathrm{l} /$ injection and EtOH density $=0.789 \mathrm{~g} / \mathrm{cm}^{3}[3,4]$. Recent reported evidence in rats suggested that this dose of alcohol may result in possible sedation, though injected in different times. In rats a dose of $0.25 \mathrm{~g} / \mathrm{kg}$ EtOH has been shown to be the lowest dose able to decrease significantly locomotion in these rodents [5]. If one considers $500 \mathrm{~g}$ the mean body weight of a male subject, this dose should correspond to $125 \mathrm{mg}$ of alcohol; a male mouse is about $1 / 25$ of a male rat, so a mouse receiving about $5 \mathrm{mg}$ of alcohol, might undergo comparable sedation effects. The experimental setting planned and performed by some Authors used ethanol in each tested sample, including controls: this should assure that sedation would be carried throughout the analysis, without influencing the net outcome of the experiment. Bias arises because ethanol is a pharmacological compound as like as gelsemine or buspirone $[3,4]$. Rodents response to ethanol may be highly variable, as like as humans [6], because of the intra-individual variability in detoxifying enzymes and non-linear BK channels 2 function [7,8]; its pharmacokinetics is complex, it does not depend on mouse strain and administration route, it has a dose-dependent linear increase in alcohol concentration in the plasma and brain and non linear or parabolic increase in the area under ethanol pharmacokinetic curve in tissues [9]. In the experimental conditions described above, it is difficult to assess if ethanol might exert a significant effect on pharmacokinetics of other drugs such as ergot alkaloids contained in Gelsemium plant extracts or buspirone, but what is well known is that ethanol possesses a significant influence on plasma pharmacokinetics of drugs, in a general way [10]. Furthermore, the effects of ethanol are often biphasic (stimulatory/inhibitory) as like as low doses of a plant extract [11], so rendering more complex any possible interpretation of the assay $[12,13]$. The association of ethanol with a different drug might change dramatically the fashion by which the drug operates in the behavioral test and a molecular or cellular comparison with the same molecule diluted into water $[2,14]$ should not have been made, unless considering the introduction of a set of controls without ethanol. So, I wondered: why to use ethanol if homeoepathic remedies use lactose globuli? Other concerns are the choice for behavioral tests.

Within this experimental condition open field test (OFT) and light-dark box test (LDT) were unable to discriminate sedation or anxiolysis by evaluating locomotor or exploratory activity by alone, due to ethanol interference. Gelsemium sempervirens Ait. alcoholic extract contains many other ergot alkaloids besides gelsemine, most of which exert many depressant and sedative effects [15,16]. Several reports dealing with herbal extracts in animal anxiety models are limited to the simplest standardized behavioral tests, which are indicated to measure locomotion and exploratory tendency as main parameters of a non-anxious behavior: in this context a decrease in these two parameters might be associated with other hallmarks, such as sedation or depression, then demonstrating that the complex mixture of compounds contained in the alcoholic plant extract may show many different pharmacological effects. Furthermore, when low doses of a plant-derived compound are used, hormetic effects may arise. Hormetic mechanisms have been described by using a broad panel of behavioral tests; the analysis revealed that hormetic-like biphasic dose-response were commonly 3 observed across all screening tests [11]. These issues normally hamper a clear description of the anxiety-like behavior in tested animals, especially if environmental conditions are considered [17]. For example, dark box in LDT may be felt by mice as an aversive environment, so forcing the animal in spending more time in the lit arena and the lit area, if has the same light exposure of the whole environment, might do not elicit any aversive stimulus $[4,18,19]$. So, which is anxiety in laboratory rodents? Is the term anxiety interchangeable with fear, stress, panic or danger sensitivity? In animals, fear is an adaptive response that has evolved to provide protection from potential harmful environments. and fearrelated behaviors in mice have long been investigated as potential models of anxiety disorders [20]. When fear is disproportionate in facing the harmful situation, it can lead to an anxiety disorder [21]. In laboratory animals, such as mice or rats, fear may be acquired when a neutral conditioned stimulus is paired with an aversive unconditioned stimulus and, usually, after several such pairings, the subjects is able to learn that the conditioned stimulus elicits several fear responses: in this circumstance, anxiety may arise [21]. This possibility occurs when the same operator makes serial injections and performs behavioral tests [4]. Research about the extinction of Pavlovian fear responses is yielding important information about the neural substrates of anxiety disorders, such as phobias and post-traumatic stress disorder (PTSD), even in humans. An advantage of the fear extinction model is that comparison of animal studies should suggest a considerable similarity between the neural structures which are involved in extinction in rodents and in humans. These studies allow to understand the neural mechanisms underlying behavioral interventions that suppress fear, including exposure therapy in anxiety disorders [22]. Fear and anxiety appear, therefore, as two different and strictly related paradigms in neuroscience. In laboratory, several behavioral tests are available to

*Corresponding author: Salvatore Chirumbolo, Department of MedicineSection D, Ospedale Civile Maggiore-Lato Mameli-Ospedale Geriatrico, Italy, Tel: 390458128456; E-mail: salvatore.chirumbolo@univr.itn

Received November 01, 2011; Accepted November 16, 2011; Published November 17, 2011

Citation: Chirumbolo S (2011) Behavioral Tests on Murine Models with Gelsemium sempervirens. Clin Exp Pharmacol 1:101. doi:10.4172/2161-1459.1000101

Copyright: $\odot 2011$ Chirumbolo S. This is an open-access article distributed under the terms of the Creative Commons Attribution License, which permits unrestricted use, distribution, and reproduction in any medium, provided the original author and source are credited. 
Citation: Chirumbolo S (2011) Behavioral Tests on Murine Models with Gelsemium sempervirens. Clin Exp Pharmacol 1:101. doi:10.4172/21611459.1000101

Page 2 of 2

ascertain if the researcher is investigating a fear extinction mechanism, an anxiety disorder or an extinction of both, due to a pharmacological treatment. One good test is elevated plus-maze. Fear can be measured as a decreased percentage of time spent on open-arm exploration in the elevated plus-maze and can be potentiated by prior inescapable stressor exposure, although not by escapable stress. In this case, the application of fear potentiated plus-maze behavior has several advantages as compared to more traditional animal models of anxiety, such as LDT or OFT [4]. The traditional, elevated plus-maze is able to measure innate fear of open spaces but a fear-potentiated plus-maze behavior should reflect an enhanced anxiety state, called as allostatic state. This typical "state of anxiety" can be defined as an unpleasant emotional arousal in face of threatening demands or dangers [23]. Actually, a cognitive appraisal of threat is a prerequisite for the experience of this type of emotion. The fear-potentiated plus-maze behavior is sensitive to proven/putative anxiolytics and anxiogenics which act via mechanisms related to the benzodiazepine-gamma-aminobutyric acid receptor, but it is also sensitive to corticotropin-releasing receptor antagonists and glucocorticoid receptor antagonists and serotonin receptor agonists/ antagonists complex [23]. In this strategy, neural mechanisms involved in contextual fear conditioning, fear potentiation and state anxiety can be studied, so rendering fear-potentiated plus-maze behavior a valuable measure in the understanding of neural mechanisms involved in the development of anxiety disorders and in the search for novel anxiolytics [23-25]. This assumption would like to suggest to better evaluate different behavioral tests in investigating anxiety-like models in animals, attempting to elicit biases at the lowest frequency possible, not to create a possible "integrate behavioral assay". For the many reasons previously indicated, the interpretation of behavioral tests includes many tricky issues [2]. Statements and comments about the possible effectiveness of low concentrated alkaloids from alcoholic plant extracts have to be reappraised and evaluated at the light of bias analysis [26]. Anxiety-like models in laboratory animals such as rodents contain many unresolved and puzzling aspects that merit to be explained by using increasingly sophisticated approaches, aiming at not lapsing into easy conclusions.

\section{References}

1. Chirumbolo S(2011) Gelsemine and Gelsemium sempervirens L. Extracts in Animal Behavioral Test: Comments and Related Biases. Front Neurol: 2-31.

2. Bellavite $P$ (2011) Gelsemium sempervirens and animal behavioral models. Front Neurol 2: 56 .

3. Bellavite P, Magnani P, Zanolin E, Conforti A(2009) Homeopathic Doses of Gelsemium sempervirens improve the Behavior of Mice in Response to Novel Environments. Evid Based Complement Alternat Med 5: 56-76.

4. Magnani P, Conforti A, Zanolin E, Marzotto M, Bellavite P (2010) Doseeffect study of Gelsemium sempervirens in high dilutions on anxiety-related responses in mice. Psychopharmacology (Berl) 210: 533-545.

5. Chuck TL, McLaughlin PJ, Arizzi-LaFrance MN, Salamone JD, Correa M (2006) Comparison between multiple behavioral effects of peripheral ethanol administration in rats: sedation, ataxia, and bradykinesia. Life Sci 79: 154-161.

6. Fraser AG, Rosalki SB, Gamble GD, Pounder RE (1995) Inter-individual and intra-individual variability of ethanol concentration-time profiles: comparison of ethanol ingestion before or after an evening meal. $\mathrm{Br} \mathrm{J}$ Clin Pharmacol 40: $387-$ 392.

7. Nelson D, Zeldin D, Hoffman S, Maltais S, Wain H, et al. (2004) Comparison of cytochrome P450 (CYP) genes from the mouse and human genomes, including nomenclature recommendations for genes, pseudogenes and alternative-splice variants Pharmacogen 14: 1-18.

8. Treistman SN, Martin GE (2009) BK channels. Mediators and models for alcohol tolerance. Trends Neurosci 32: 629-637.

9. Golovenko NY, Zhuk MS, Zin'kovskii VG, Zhuk OV, Kopanitsa MV (2001)
Pharmacokinetics of ethanol in mice with different alcohol motivation. Bull Exp Biol Med 132: 852-855.

10. Lennernas H (2009) Ethanol-drug absorption interaction: potential for a significant effect on the plasma pharmacokinetics of ethanol vulnerable formulations. Mol Pharmaceut 6: 1429-1440.

11. Calabrese EJ (2008) An assessment of anxiolytic drug screening tests: hormetic dose responses predominate. Crit Rev Toxicol. 38: 489-542.

12. Middaugh L. D, Boggan W. O, Randall C. L (1987) Stimulatory effects of ethanol in C57BL/6 mice. Pharmacol. Biochem. Behav. 3: 421-424.

13. Crabble JC jr, Johnson NA, Gray DK, Kosobud A, Young ER (1982) Biphasic effects of ethanol on open-field activity: sensitivity and tolerance in C57BL/6N and DBA/2N mice. J Comp Physiol Psychol 96: 440-451.

14. Venard C, Boujedaini N, Mensah-Nyagan A. G, Patte-Mensah C (2009) Comparative analysis of gelsemine and Gelsemium sempervirens activity on neurosteroid allopregnanolone formation in the spi-nal cord and limbic system. Evid. Based Complement. Alternat. Med.

15. Duke JA (1992). Handbook of phytochemical constituents of GRAS herbs and other economic plants.

16. Gahlot K, Abid M, Sharma A (2011) Pharmacological evaluation of Gelsemium sempervirens roots for CNS depressant activity. Int J Pharmatech Res 3: 693697.

17. Lewejohann L, Reinhard C, Schrewe A, Brandewiede J, Haemisch A et al. (2006) Environmental bias? Effecs of housing conditions, laboratory environment and experimenter on behavioral tests Genes Brain Behav 5: 6472.

18. Hascoet M, Bourin M (1998) A new approach to the light/dark test procedure in mice. Pharmacol Biochem Behav 60: 645-653.

19. Bourin M, Hascoet M (2003) The mouse light/dark box test Eur J Phrmacol 463: 55-65.

20. Hettema JM, Webb BT, Guo AY, Zhao Z, Maher BS et al. (2011) Prioritization and Association Analysis of Murine-Derived Candidate Genes in AnxietySpectrum Disorders. Biol Psychiatry 70: 888-896.

21. Graham BM, Milad MR (2011) The Study of Fear Extinction: Implications for Anxiety Disorders.Am J Psychiatry.

22. Chang CH, Knapska E, Orsini CA, Rabinak CA, Zimmerman JM,et al. (2009) Fear extinction in rodents. Curr Protoc Neurosci. Chapter 8: Unit8.23.

23. Korte SM, De Boer SF (2003) A robust animal model of state anxiety: fearpotentiated behaviour in the elevated plus-maze. Eur J Pharmacol 463:163175

24. Korte SM, De Boer SF, Bohus B (1999) Fear- potentiation in the elevated plusmaze test depends on stressor controllability and fear conditioning. Stress 3 27-40.

25. Grahn RE, Kalman BA, Brennan FX, Watkins LR, Maier SF (1995) The elevated plus-maze is not sensitive to the effect of stressor controllability in rats. Pharmacol. Biochem. Behav. 52: 565-570.

26. Podsakoff PM, MacKenzie SB, Lee JY, Podsakoff NP (2003) Common method biases in behavioral research: a critical review of the literature and recommended remdies J Appl Psychol 88: 879-903. 